\title{
Subclinical cardiac alterations detected by echocardiographyin Mexican schoolchildren with overweight and obesity
}

\section{Alteraciones cardíacas subclínicas detectadas por ecocardiografía en escolares Mexicanos con sobrepeso y obesidad}

Daniel Hurtado-Sierra ${ }^{1}$, Eloísa Colin-Ramírez ${ }^{2,3}$, Elisa L. Lena-Hernández¹, Catalina Sánchez-Cornelioł, Laura Trujeque-Ruiz', Tania I. Aguilar-Morales², Israel García-Dávalos ${ }^{1}$, Maite Vallejo², and

Clara A. Vázquez-Antona ${ }^{1 *}$

${ }^{1}$ Department of Pediatric Echocardiography; ${ }^{2}$ Department of Sociomedical Research, Instituto Nacional de Cardiología Ignacio Chavez; ${ }^{3} \mathrm{CON} A \mathrm{C} Y T$

Professorship Directorate, Consejo Nacional de Ciencia y Tecnología, Mexico City, Mexico

\begin{abstract}
Objective: The purpose of this study was to evaluate early changes in myocardial function in overweight and obese chitdren without hypertension. Methods: This was a cross-sectional study involving 150 participants of both sexes between 6 and 15 years old. Anthropometric and biochemical evaluations were performed. Ventricular function was assessed by conventional echocardiographic methods and myocardial deformation analysis by two-dimensional speckle tracking echocardiography. One-way analysis of variance was employed for the global comparison of study variables between groups (childrentwith normal weight, overweight, and obesity), and post hoc analysis with Bonferroni correction was used for multiple comparisons, considering normal weight children as the reference category. Results: Overall, 142 participants were included, 50 (35\%) with normal weight, 39 (28\%) overweight, and $53(37 \%)$ obesity. The diastolic diameter of the left ventricular and interventricular septum, and diameter of the left atrium and LV mass were significantly higher in children with obesity compared to those with normal weight. No significant differences in the conventional indicators of LV systolic and diastolic function were found between groups. Significant differences in the regional myocardial deformation between the three groups were observed. Mean global longitudinal myocardial deformation was smaller in patients with obesity $(-20.9 \%$ vs. $-23.5 \%, p<0.05)$ compared to children with normal weight. Conclusions: The childhood obesity was associated with altered myocardial deformation, even in the presence of normal ejection fraction. Myocardial deformation evaluation is relevant in the assessment of pediatric patients with obesity.
\end{abstract}

Key words: Childhood obesity. Myocardial function. Echocardiography. Myocardial deformation. Speckle tracking. Mexiề.

\section{Correspondence:}

*Clara A. Vázquez-Antona

Juan Badiano, 1

Col. Sección 16

Date of reception: 20-09-2018

C.P. 14080 , Ciudad de México, México

E-mail: cvazquezant@yahoo.com.mx E-mail: cvazquezant@yahoo.com.mx DOI: 10.24875/ACME.M19000051 www.archivoscardiolog
2604-7063/@ 2019 Instituto Nacional de Cardiología Ignacio Chávez. Published by Permanyer. This is an open access article under the CC BY-
license (http://creativecommons.org/licenses/by-nc-nd/4.0/).

Available online: 06-05-2019 Arch Cardiol Mex (Eng). 2019;89(3):202-211 www.archivoscardiologia.com 


\section{Resumen}

Objetivo: El propósito de este estudio fue evaluar los cambios tempranos en la función miocárdica en niños con sobrepeso y obesidad, sin hipertensión arterial. Métodos: Estudio transversal en el que se incluyeron 150 participantes de ambos sexos entre 6 y 15 años. Se realizaron evaluaciones antropométricas, bioquímicas y de función ventricular mediante métodosẹcocardiográficos convencionales y análisis de deformación miocárdica con ecocardiografía bidimensional speckle tracking. La comparación global entre los grupos de estudio (niños con peso normal, sobrepeso y obesidad) se llevó a cabo cen la prueba de análisis de varianza (ANOVA) de una vía y análisis post hoc con corrección de Bonferroni para las comparaciones múltiples, y se consideró a los niños con peso normal como grupo de referencia. Resultados: La muestra final fue dë142 participantes, 50 (35\%) con peso normal, 39 (28\%) con sobrepeso y 53 (37\%) con obesidad. El diámetro diastólico detwentrículo izquierdo (VI) y el septum interventricular, y el diámetro de la aurícula izquierda (Al) y la masa del VI fueron significativamente más altos en el grupo con obesidad en comparación con el grupo con peso normal. No se observaron diferencias significativas en los indicadores convencionales de la función sistólica y diastólica ventricular izquierda. Se- observaron diferencias significativas en la deformación miocárdica regional entre los tres grupos. La media de deformación miocárdica longitudinal global fue más baja en los pacientes con obesidad $(-20.9 \%$ vs. $-23.5 \%$; $p<0.05)$ en comparación con los niños con peso normal. Conclusiones: La obesidad infantil se asoció a alteraciones en la deformación miocáraica, incluso en presencia de fracción de expulsión normal. La evaluación de la deformación miocárdica es relevante en loš pacientes pediátricos con obesidad.

Palabras clave: Obesidad infantil. Función miocárdica. Ecocardiografía. Deformación miocárdica. Speckle tracking. México.

\section{Introduction}

Childhood obesity is a public health problem that has been increasing over the past three decades in the world ${ }^{1}$. In Mexico, the combined prevalence of obesity and overweight at school age is 33.2\% (15.3 and 17.9\%, respectively), according to the 2016 National Health and Nutrition Survey².

Excess weight can affect different organs and systems, with serious consequences, such as hypertension, diabetes mellitus, dyslipidemia, fatty liver, and psychosocial problems, among others ${ }^{3}$. In addition, early development of arteriosclerotic lesions such as fibrous plaques and fatty stretch marks in the aorta and coronary arteries has been observed in children with obesity, which increases the risk of myocardial infarction in adulthood ${ }^{4-8}$.

Echocardiographic studies in adults with obesity have demonstrated structural and functional alterations, such as left atrium (LA) and left ventricle (LV) dilation, as well as LV hypertrophy and global dysfunction? ${ }^{9}$. Through the evaluation of myocardial deformation, early LV functional alterations have been able to be detected in the presence of a normal ejection fraction (left ventricular ejection fraction [LVEF]) ${ }^{10,11}$. However, in the children's population, early changes in the myocardial function associated with obesity have been less studied $^{12-16}$. Detection of early subclinical alterations is essential for cardiovascular risk secondary prevention strategies to be implemented and to reduce the expenses deriving from health care at later ages ${ }^{17}$.
The purpose of this study was to identify early changes in the myocardial function in children with overweight and obesity and without hypertension, through evaluation of longitudinal myocardial deformation (strain), with the speckle tracking echocardiographic method.

\section{Methods}

\section{Study population}

A cross-sectional study was conducted that included 150 participants of both genders, aged between 6and 15 years, who were recruited through a call addressed to children of workers of the National Institute of Cardiology "Ignacio Chávez" Instituto Nacional de Cardiología Ignacio Chávez (INCICh) and pupils of elementary schools from the Southern area of Mexico Eity, between July 2015 and February 2017. The participants attended the INCICh Socio-medical Research area for initial assessment and eligibility criteria confirmation. Participants with underweight, hypertension, congeñital heart diseases, diabetes mellitus, renal disease, ต̄eoplasms or systemic inflammatory diseases were excluded from the study. Once non-echocardiographic eligibility criteria were confirmed, the participants were scheduled for echocardiographic assessment at uthe INCICh pediatric echocardiography department.

The study was approved by the INCICh Research and Ethics Committees. Informed consent was obtained from parents or legal guardians, as well as assent of the child to participate in the study. 


\section{Assessments}

Anthropometry. Weight and height assessment was carried out in accordance with the guidelines described by the International Society for the Advancement of Kinanthropometry for anthropometric evaluation ${ }^{18}$, with the child without shoes and dressed in a light gown. For weight measurement, a mechanical column scale (SECA 700 ), with a precision of $0.05 \mathrm{~kg}$ and maximum capacity of $220 \mathrm{~kg}$, was used. Height was evaluated with a stadiometer (SECA 220), with a measurement range of 60$200 \mathrm{~cm}$ and 1-mm precision. The Z-score for body mass index was calculated and classified with the World Health Organization growth standards specific for age and gender $^{19}$. Overweight was defined as a Z-score $>+1$ standard deviations (SD), and obesity as a Z-score $>+2$ SD.

Blood pressure. Blood pressure was measured in the left arm on three occasions, with intervals of $3 \mathrm{~min}$ between each measurement, and with the child at rest for not $<10 \mathrm{~min}$, in a sitting position before the first evaluation. A previously-calibrated mercury sphygmomanometer and a bracelet according to the child's age were used, following the recommendations for manual blood pressure measurement in the pediatric patient ${ }^{20}$. The presence of hypertension was defined as the average of three measurements of systolic, diastolic blood pressure, or both, equal to or above percentile $95+$ $5 \mathrm{mmHg}$ for gender, age, and height ${ }^{20}$.

Biochemical evaluation. After a 12-h fasting, serum glucose, triglycerides (TG), total cholesterol, low-density lipoprotein (LDL) cholesterol, high-density lipoprotein (HDL) cholesterol, atherogenic index, serum creatinine, and uric acid levels were measured.

Echocardiography. The acquisition of images and measurements during post-processing was carried out by three echocardiography expert physicians, trained and certified in the technique, using an echocardiographic Philips iE33 xMatrix equipment, in the $M$, two-dimensional (2D), three-dimensional (3D), pulsed, continuous and color Doppler modalities, as well as tissue Doppler imaging (TDI), using 5 and $7 \mathrm{MHz}$ transducers. LA and LV, LV mass (LVm), 3D LVm, LVEF, LV shortening fraction, 3D LVEF, 3D LV end-diastolic volume, transmitral flow pulsed-wave Doppler and myocardial performance indexes measurements, with their respective Z-scores, were carried out with $\mathrm{TDI}^{21,22}$. The $Z$-scores for LV dimension and function measurements, adjusted to the body surface area, were calculated taking as reference a USA population of children and adolescents ${ }^{21}$, since so far there are no standards for the Mexican population.
Post-processing for myocardial deformation analysis and $3 \mathrm{D}$ volumetric quantification was performed on the workstation with the QLAB 10.3.1 program (Phillips Healthcare $\left.{ }^{\circledR} 2001-2014\right) .2 D$ echocardiography with the speckle tracking technique was used. Tracing was performed with the block matching method.

LV overall longitudinal deformation was obtained as an average of chambers 4,3 , and 2 apical projections $^{23,24}$. The capture of images was carried out automatically followed by manual correction of the assessed region. Measurements accepted by the equipment șoftware, or those that were not accepted by the software but that could be manually corrected (less than two segments) were considered adequate. A proper acôustic window and precise synchronization with the child's breathing pattern, which would avoid oscillation of the heart within the chest, was necessary for correct $2 D$ image acquisition.

\section{Statistical analysis}

The sample size was calculated considering a clinically relevant minimal difference of $2.3 \%(-18 . \overline{2} \pm$ 2.0 vs. $-20.5 \pm 2.3$ ) for LV myocardial longitudinal strain between children with obesity and normal weight, as reported by Mangner et al. ${ }^{12}$. In addition, a two-tailed alpha of $5 \%, 95 \%$ power, and a non-response rate of $20 \%$ were considered, with a total of 58 children (28 per group) being calculated. Due to the inclusion of three groups in the present study (children with normal weight, overweight, and obesity), the estimated total sample size was $28 \times 3=84$.

The results are presented as means \pm SD for continuous variables and as absolute and relative frequencies for categorical variables. For the overall comparison of continuous variables between study groups (children with normal weight, overweight, and obesity), a oneway analysis of variance (ANOVA) was used. Bonferroni's post hoc analysis with correction was used for multiple between-group comparisons of the continuous variables that showed a significant difference in the overall comparison, with the children with normal weight being considered as the reference group. For the comparison of categorical variables, Pearson's Chi-square test was used. The echocardiographic indicators that showed a significant difference between groups on the bivariate analysis were subsequently tested in a covariance analysis, including age, height, and gender as covariates. Adjusted means were presented with the corresponding $95 \%$ confidence intervals. A difference was considered statistically significant when $p<0.05$. 
Table 1. General characteristics of the population by study group

\begin{tabular}{|c|c|c|c|c|}
\hline & $\begin{array}{l}\text { Patients with normal weight } \\
\qquad(\mathrm{n}=50)\end{array}$ & $\begin{array}{l}\text { Patients with overweight } \\
\qquad(\mathrm{n}=39)\end{array}$ & $\begin{array}{l}\text { Patients with obesity } \\
\qquad(\mathrm{n}=53)\end{array}$ & p-value* \\
\hline Age (years) & $9.4 \pm 2.5$ & $9.4 \pm 1.8$ & $9.8 \pm 1.8$ & $0.51 \underline{E}$ \\
\hline BMI (kg/[height]²) & $16.9 \pm 1.7$ & $20.6 \pm 1.8^{\ddagger}$ & $25.6 \pm 3.7^{\dagger}$ & $<0.001$ \\
\hline BMI Z-score $\left(\mathrm{kg} /[\text { height }]^{2}\right.$ ) & $0.05 \pm 0.6$ & $1.4 \pm 0.3^{\ddagger}$ & $2.6 \pm 0.4^{\dagger}$ & $<0.001$ \\
\hline $\mathrm{SBP}(\mathrm{mmHg})$ & $94 \pm 10.7$ & $97 \pm 7.6$ & $97 \pm 20.9$ & 0.587 \\
\hline $\mathrm{DBP}(\mathrm{mmHg})$ & $62 \pm 8.2$ & $64 \pm 5.7$ & $63 \pm 13.8$ & $0.68 \overline{7}$ \\
\hline Glu (mg/dL) & $90 \pm 6.2$ & $90 \pm 4.1$ & $91 \pm 5.9$ & $0.35 \overline{9}$ \\
\hline $\mathrm{TC}(\mathrm{mg} / \mathrm{dL})$ & $160 \pm 24.2$ & $163 \pm 26.7$ & $164 \pm 27.7$ & $0.64 \underline{\underline{6}-}$ \\
\hline $\mathrm{HDL}(\mathrm{mg} / \mathrm{dL})$ & $58 \pm 12.7$ & $49 \pm 11.4^{\ddagger}$ & $45 \pm 8.7^{\dagger}$ & $<0.005$ \\
\hline LDL (mg/dL) & $95 \pm 22.1$ & $104 \pm 24.6$ & $109 \pm 24.7^{\dagger}$ & 0.025 \\
\hline TGL (mg/dL) & $77 \pm 34.3$ & $95 \pm 39.9$ & $132 \pm 49.2^{\dagger}$ & $<0.001$ \\
\hline
\end{tabular}

BMI: body mass index; DBP: diastolic blood pressure; Glu: glucose; HDL: high-density lipoprotein cholesterol; LDL: low-density lipoprotein cholesterol; SBP: systolic blood pressure; TC: total cholesterol; TGL: triglycerides.

Values are presented as means for continuous variables with their standard deviation.

* Overall comparison between groups with the ANOVA test.

${ }^{t} p<0.05$ for the comparison of the obesity group versus normal weight group.

${ }^{\ddagger} p<0.05$ for the comparison of the overweight group versus normal weight group.

\section{Results}

A total of 150 patients were recruited, out of which eight were excluded from the study, two for incomplete data, three for diagnosis of congenital heart disease on the echocardiographic study, and three due to an inadequate acoustic window, which did not allow quality image acquisition. The final sample comprised 142 participants, 77 females and 65 males, 50 with normal weight (35\%), 39 with overweight $(28 \%)$, and 53 with obesity $(37 \%)$. Mean age and gender distribution were similar between groups. There were no significant differences in blood pressure between the three groups (Table 1).

HDL cholesterol mean serum concentration was significantly lower in children with obesity than in those with normal weight $(45 \mathrm{mg} / \mathrm{dL}$ vs. $58 \mathrm{mg} / \mathrm{dL} ; \mathrm{p}<0.05)$. In addition, LDL cholesterol (109 mg/dL vs. $95 \mathrm{mg} / \mathrm{dL}$; $\mathrm{p}<0.05$ ) and TG means (132 mg/dL vs. $77 \mathrm{mg} / \mathrm{dL}$; $p<0.05)$ were significantly higher in children with obesity in comparison with those with normal weight. In the group of children with overweight, there was a significant difference only in HDL cholesterol concentrations, which were lower in this group than in children with normal weight $(49 \mathrm{mg} / \mathrm{dL}$ vs. $58 \mathrm{mg} / \mathrm{dL} ; \mathrm{p}<0.05)$. No significant differences were observed in the glucose serum levels between the three groups (Table 1).

When the echocardiographic dimensions obtained on $\mathrm{M}$ mode were compared, there were significant differences between the three groups in the LV diastolic diameter, the interventricular septum, and the LA diämeter; however, no differences were observed in the Z-score for neither of these dimensions (Table 2). After the post hoc analysis, the overweight group showed a higher mean LV diastolic diameter, in comparison with the group with normal weight, with no significant differences in the remaining parameters assessed. In turn, LA diastolic diameter and interventricular septum, LA diameter and LVm means were significantly higher in the group with obesity in comparison with the group with normal weight. In the latter group, not only assignificant difference in LVm was observed but also in the corresponding Z-score.

Regarding the 3D echocardiographic evaluation, a significantly higher mean diastolic volume $\left(57.2\right.$ vs. $44.9 \mathrm{~cm}^{3}$; $\mathrm{p}<0.05)$ and 3D LVm (90.7 vs. $60.8 \mathrm{~g} ; \mathrm{p}<0.05)$ were observed in the group with obesity in comparison with the normal weight group. In turn, the group with overweight showed a higher $3 \mathrm{D} \mathrm{LVm}$ mean than the normal weight group (76.8 vs. $60.8 \mathrm{~g} ; \mathrm{p}<0.05)$ (Table 2).

No significant differences were observed in the means of LV systolic and diastolic function conventional indicators between groups (Table 3).

Regarding the study of myocardial regional strain, there were significant differences between all three groups in eight of the 17 ventricular segments evaluated $^{25}$. A lower mean myocardial deformation-was 
Table 2. LV dimensions, mass and 3D measurements by study group

\begin{tabular}{|c|c|c|c|c|}
\hline & $\begin{array}{l}\text { Patients with normal weight } \\
\qquad(n=50)\end{array}$ & $\begin{array}{l}\text { Patients with overweight } \\
\qquad(\mathrm{n}=39)\end{array}$ & $\begin{array}{l}\text { Patients with obesity } \\
\qquad(\mathrm{n}=53)\end{array}$ & p-value* \\
\hline LV (mm) & $25.9 \pm 3.3$ & $26.8 \pm 4.8$ & $28.9 \pm 5.0^{\dagger}$ & \\
\hline LV Z-score & $0.94 \pm 0.85$ & $0.95 \pm 0.94$ & $0.84 \pm 1.04$ & 0.81 \\
\hline LVDD (mm) & $39.1 \pm 3.8$ & $41.7 \pm 4.3^{\ddagger}$ & $42.2 \pm 4.3^{\dagger}$ & \\
\hline LVDD Z-score & $-0.5 \pm 0.66$ & $-0.27 \pm 0.75$ & $-0.55 \pm 0.91$ & \\
\hline LVSD (mm) & $24.7 \pm 2.8$ & $26.1 \pm 3.7$ & $26.6 \pm 5.0$ & \\
\hline LVSD Z-score & $-0.2 \pm 0.82$ & $-0.23 \pm 0.77$ & $-0.18 \pm 0.92$ & \\
\hline IVSD (mm) & $6.7 \pm 1.2$ & $7.0 \pm 1.4$ & $7.5 \pm 1.5^{\dagger}$ & \\
\hline IVSD Z-core & $0.27 \pm 0.77$ & $0.35 \pm 0.71$ & $0.19 \pm 1.5$ & 0.80 \\
\hline PWD mm & $7.6 \pm 1.2$ & $6.6 \pm 1.0$ & $8.3 \pm 1.3$ & \\
\hline PWD Z-score & $0.38 \pm 0.7$ & $0.33 \pm 0.88$ & $0.40 \pm 0.7$ & \\
\hline LV mass (g) & $75.6 \pm 25.9$ & $83.1 \pm 24.2$ & $104.4 \pm 29.1^{\dagger}$ & $<0.00$ \\
\hline LV mass Z-score & $-0.78 \pm 1.1$ & $-0.48 \pm 1.1$ & $0.28 \pm 1.1^{\dagger}$ & $<0.0$ \\
\hline LV mass $\left(\mathrm{g} / \mathrm{m}^{2}\right)$ & $66 \pm 20.6$ & $66 \pm 12.5$ & $71.3 \pm 13.5$ & \\
\hline 3D LVED vol. $\left(\mathrm{cm}^{3}\right)$ & $44.9 \pm 15.9$ & $50.7 \pm 15.1$ & $57.2 \pm 24.9^{\dagger}$ & 0.01 \\
\hline 3D LV mass (g) & $60.8 \pm 21.4$ & $76.8 \pm 22.8^{\ddagger}$ & $90.7 \pm 31.3^{\dagger}$ & \\
\hline
\end{tabular}

IVSD: interventricular septum diameter in diastole; LA: left atrium; LV: left ventricle; LVDD: left ventricle diastolic diameter; LVED Vol.: left ventricle end-diastolic volume; LVSD: left ventricle systolic diameter; PWD: posterior wall diastolic diameter.

Values presented in means for continuous variables with their standard deviation.

*Overall comparison between groups with the ANOVA test.

${ }^{t} p<0.05$ for the comparison of the group with obesity versus normal weight group.

${ }^{\ddagger} p<0.05$ for the comparison of the group with overweight versus normal weight group.

observed in ventricular segments $4,7,10,13,14,15$, 16 , and 17 in the group with obesity in comparison with the normal weight group, whereas in the group with overweight, only ventricular segments $13,14,16$, and 17 showed a lower myocardial strain mean in comparison with the normal weight group. Mean myocardial global longitudinal strain was lower both in patients with obesity $(-20.9$ vs. $-23.5 \% ; p<0.05)$ and in those with overweight $(-21.9$ vs. $-23.5 ; p<0.05)$, in comparison with the children with normal weight (Table 4).

The differences found between the groups of children with obesity and normal weight in LV dimensions and 3D LVm and 3D diastolic volume continued to be statistically significant after being adjusted for age, gender, and height. Similarly, myocardial deformity in all four affected ventricular segments of patients with overweight $(13,14$, 16 , and 17) and in 6 of the 8 compromised segments in the group of patients with obesity $(4,7,13,14,16$, and 17), maintained a significant difference in comparison with the group with normal weight after adjusting for age, gender, and height (Table 5).

\section{Discussion}

The combined prevalence of obesity and overweight in Mexico continues to be high, and it affects up to onethird of children older 5 than years, without significant changes being observed when the 2012 and 2016 $\mathrm{Na}$ tional Health and Nutrition Surveys are compared

Obesity and overweight almost epidemic proportions in Mexican children are attributed to cultural, economic, demographic, and environmental changes in recent years. Although genetic and hormonal disorders arerisk factors for the development of obesity and overweight, dietary factors in Mexican children are more important, such as the widespread consumption of sugary and carbonated drinks instead of water, accessibility to densely energetic foods at low price, high consumption of saturated fats with low protein and fiber intake, as well as a sedentary lifestyle, with a marked decrease in the practice of physical activity outdoors ${ }^{26}$. Low birth weight, breastfeeding period short duration, poverty, migration from rural to urban areas, mistaken concepts 
Table 3. Indicators of left ventricular systolic and diastolic function by study group

\begin{tabular}{|c|c|c|c|c|}
\hline & $\begin{array}{l}\text { Patients with normal weight } \\
\qquad(n=50)\end{array}$ & $\begin{array}{l}\text { Patients with overweight } \\
\qquad(\mathrm{n}=39)\end{array}$ & $\begin{array}{l}\text { Patients with obesity } \\
\qquad(\mathrm{n}=53)\end{array}$ & p-value* \\
\hline $\operatorname{LVEF}(\%)$ & $64.5 \pm 4.6$ & $65.2 \pm 5.1$ & $64.1 \pm 5.9$ & $0.608 \bar{C}$ \\
\hline 3D LVEF (\%) & $62.1 \pm 7.2$ & $66.9 \pm 18.8$ & $63.8 \pm 7.1$ & 0.173 \\
\hline LV SF $(\%)$ & $36.4 \pm 6.9$ & $37.8 \pm 7.0$ & $38.0 \pm 8.6$ & 0.5370 \\
\hline M E/A ratio & $1.7 \pm 0.3$ & $2.1 \pm 1.7$ & $1.7 \pm 0.8$ & $0.120-$ \\
\hline $\mathrm{M}$ E/A ratio Z-score & $-0.24 \pm 0.31$ & $0.03 \pm 0.77$ & $-0.21 \pm 0.82$ & $0.20 \overline{\overline{7 n}}$ \\
\hline Left lat. Tei & $0.40 \pm 0.08$ & $0.41 \pm 0.07$ & $0.45 \pm 0.42$ & 0.662 \\
\hline Left lat. Tei Z-score & $0.38 \pm 0.79$ & $2.1 \pm 9.4$ & $0.55 \pm 1.1$ & 0.214 \\
\hline Left med. Tei & $0.38 \pm 0.08$ & $0.4 \pm 0.1$ & $0.41 \pm 0.12$ & 0.282 \\
\hline Left med. Tei Z-score & $0.34 \pm 0.86$ & $0.59 \pm 1$ & $0.68 \pm 1.3$ & 0.304 巨్ \\
\hline \multicolumn{5}{|c|}{$\begin{array}{l}\text { Left lat. Tei: left lateral Tei index; Left med. Tei: left medial Tei index; LV SF: left ventricular shortening fraction; LVEF: left ventricular ejection fraction; M E/A: mitral } \\
\text { E/A-waves ratio. } \\
\text { Values are presented as means for continuous variables with their standard deviation. } \\
\text { *Overall comparison between groups with the ANOVA test. } \\
\text { Table 4. LV myocardial segmental and global longitudinal strain by study groups }\end{array}$} \\
\hline
\end{tabular}

\begin{tabular}{|c|c|c|c|c|}
\hline Segment & $\begin{array}{l}\text { Patients with normal weight } \\
\qquad(\mathrm{n}=50)\end{array}$ & $\begin{array}{l}\text { Patients with overweight } \\
\qquad(\mathrm{n}=39)\end{array}$ & $\begin{array}{l}\text { Patients with obesity } \\
\qquad(n=53)\end{array}$ & p-value* \\
\hline 1 & $-21 \pm 5.7$ & $-23 \pm 6.8$ & $-20 \pm 8.1$ & 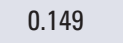 \\
\hline 2 & $-19 \pm 2.9$ & $-20 \pm 5.7$ & $-19 \pm 4.4$ & $0.378 \frac{2}{ \pm}$ \\
\hline 3 & $-19 \pm 4.1$ & $-20 \pm 4.7$ & $-18 \pm 4.5$ & 0.156 \\
\hline 4 & $-21 \pm 4.3$ & $-22 \pm 5.4$ & $-18 \pm 5.5^{\dagger}$ & $0.005=$ \\
\hline 5 & $-24 \pm 4.7$ & $-25 \pm 5.7$ & $-22 \pm 3.7$ & $0.117 \bigcirc$ \\
\hline 6 & $-23 \pm 3.6$ & $-23 \pm 5.6$ & $-21 \pm 8.1$ & 0.144 \\
\hline 7 & $-22 \pm 5.7$ & $-24 \pm 6.4$ & $-18 \pm 5.5^{\dagger}$ & $<0.001$ 으 \\
\hline 8 & $-23 \pm 4.8$ & $-24 \pm 6.2$ & $-22 \pm 5.1$ & $0.140-$ \\
\hline 9 & $-22 \pm 3.7$ & $-22 \pm 5.7$ & $-21 \pm 5.0$ & $0.249 \frac{J}{J}$ \\
\hline 10 & $-22 \pm 5.2$ & $-22 \pm 6.1$ & $-19 \pm 5.1^{\dagger}$ & 0.017 은 \\
\hline 11 & $-23 \pm 4.1$ & $-21 \pm 4.7$ & $-21 \pm 4.7$ & 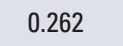 \\
\hline 12 & $-24 \pm 4.4$ & $-22 \pm 6.0$ & $-22 \pm 5.9$ & 0.297 으 \\
\hline 13 & $-24 \pm 5.5$ & $-19 \pm 6.1^{\ddagger}$ & $-19 \pm 4.8^{\dagger}$ & $<0.001 \stackrel{\odot}{\subset}$ \\
\hline 14 & $-26 \pm 4.7$ & $-23 \pm 5^{\ddagger}$ & $-23 \pm 3.9^{\dagger}$ & $0.001 \subsetneq$ \\
\hline 15 & $-26 \pm 5.2$ & $-24 \pm 5.1$ & $-23 \pm 4.3^{\dagger}$ & 0.015 ఠ \\
\hline 16 & $-24 \pm 3.9$ & $-21 \pm 3.9^{\ddagger}$ & $-20 \pm 5^{\dagger}$ & $<0.001$ 윽 \\
\hline 17 & $-25 \pm 3.7$ & $-21 \pm 3.9^{\ddagger}$ & $-21 \pm 3.8^{\dagger}$ & $<0.001 \backsim$ \\
\hline GLS (\%) & $-23.5 \pm 2.2$ & $-21.9 \pm 2.6^{\ddagger}$ & $-20.9 \pm 2.2^{\dagger}$ & $<0.001^{+}$ \\
\hline \multicolumn{4}{|c|}{$\begin{array}{l}\text { GLS: global longitudinal strain. } \\
\text { Values are presented as means for continuous variables with their standard deviation. } \\
{ }^{*} \text { Overall comparison between groups with the ANOVA test. } \\
{ }^{p}<<0.05 \text { for the comparison of the group with obesity versus normal weight group. } \\
\mathrm{f} p<0.05 \text { for the comparison of the group with overweight versus normal weight group. }\end{array}$} & 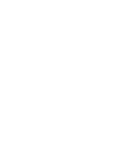 \\
\hline
\end{tabular}


Table 5. Age-, gender-, and height-adjusted means for selected indicators of LV dimensions, mass, volume, and myocardial longitudinal strain by study groups

\begin{tabular}{|c|c|c|c|c|}
\hline & $\begin{array}{l}\text { Patients with normal weight } \\
\qquad(n=50)\end{array}$ & $\begin{array}{l}\text { Patients with overweight } \\
\qquad(\mathrm{n}=39)\end{array}$ & $\begin{array}{l}\text { Patients with obesity } \\
\qquad(n=53)\end{array}$ & p-value* \\
\hline \multicolumn{5}{|c|}{ LV dimensions, mass, and two/three-dimensional volumes } \\
\hline $\mathrm{LA}(\mathrm{mm})$ & $26.1(25,27.3)$ & $26.9(25.6,28.2)$ & $28.7(27.6,29.8)^{\dagger}$ & \\
\hline LVDD (mm) & $39.2(38.3,40.1)$ & $42(41,43.1)^{\ddagger}$ & $41.8(41,42.7)^{\dagger}$ & $<0.001$ \\
\hline IVSD (mm) & $6.7(6.3,7.1)$ & $7.0(6.6,7.5)$ & $7.4(7.1,7.8)^{\dagger}$ & $0.036 \frac{\mathrm{C}}{\sim}$ \\
\hline 3D LV mass $(\mathrm{g})$ & $65.8(59.7,71.9)$ & $77.2(70.3,84.1)$ & $85.8(79.9,91.6)^{\dagger}$ & $<0.001 \overline{0}$ \\
\hline LVED vol. $\left(\mathrm{cm}^{3}\right)$ & $45.1(40.1,50.2)$ & $51.2(45.5,57)$ & $56.5(51.7,61.4)^{\dagger}$ & 0.009 \\
\hline
\end{tabular}

\begin{tabular}{|l|l|}
\hline Segment & \\
\hline 4 & $-21.8(-23.3,-20.3)$ \\
\hline 7 & $-22.9(-24.6,-21.1)$ \\
\hline 10 & $-22.3(-23.9,-20.7)$ \\
\hline 13 & $-23.8(-25.3,-22.3)$ \\
\hline 14 & $-25.9(-27.2,-24.7)$ \\
\hline 15 & $-25.9(-27.3,-24.5)$ \\
\hline 16 & $-23.9(-25.2,-22.7)$ \\
\hline 17 & $-25.2(-26.3,-24.1)$ \\
\hline GLS (\%) & $-23.3(-24,-22.6)$ \\
\hline
\end{tabular}

LV myocardial strain

GLS: global longitudinal strain; IVSD: interventricular septum diameter in diastole; LA: left atrium; LV: left ventricle; LVDD: left ventricle diastolic diameter; LVED Vol.: Ieft ventricle end-diastolic volume.

Values presented as means ( $95 \%$ confidence intervals).

${ }^{*}$ For the comparison between groups of height-, gender-, and age-adjusted means using the analysis of covariance.

${ }^{\dagger} p<0.05$ for the comparison of the group with obesity versus normal weight group.

${ }^{\ddagger} p<0.05$ for the comparison of the group with overweight versus normal weight group.

about health, parental obesity, globalization, and industrialization add up to the aforementioned factors.

To allow early and timely diagnosis of obesity-associated changes in the cardiovascular system, advanced echocardiography techniques have been used to support decisions and behaviors adopted regarding the prevention, treatment, and control of excess weight.

In the adult population, changes in the dimensions of the left cavities resulting from obesity have been reported, including LA and LV dilation, LV hypertrophy with an increase in the interventricular septum and posterior wall dimensions ${ }^{9,27}$; however, in children with overweight and obesity there is no such extensive documentation on heart structural and functional alterations.

Experimental studies have shown that hypercholesterolemia may cause LV hypertrophy through several mechanisms, which include increased endothelin one concentration, intracellular signaling activation in
$-22.3(-24,-20.5) \quad-18.8(-20.2,-17.3)^{\dagger}$

$-24.1(-26.1,-22.1) \quad-18.6(-20.3,-16.9)^{\dagger}$

$-22.2(-24,-20.3) \quad-19.5(-21,-18)$

$-19.8(-21.5,-18)^{\ddagger}$
$-19.7(-21.2,-18.3)^{\dagger}$

$-23.3(-24.7,-21.9)^{\ddagger} \quad-24.4(-25.6,-23.2)$

$-24.4(-26,-22.8) \quad-23.6(-24.9,-22.2)$

$-21.4(-22.8,-19.9)^{\ddagger}$
$-21.0(-22.2,-19.8)^{\dagger}$

$-21.8(-23.1,-20.6)^{\ddagger} \quad-21.4(-22.4,-20.3)^{\dagger}$

$-21.9(-22.7,-21.1)^{\ddagger} \quad-21.0(-21.7,-20.4)^{\dagger}$ 
the present study, significantly higher TG and lower HDL cholesterol concentrations were observed in the group of children with obesity, in comparison with the children with normal weight (Table 1).

The results of our study demonstrated significant subclinical changes in LV geometry and ventricular function in children with overweight and obesity and without hypertension. The number of compromised echocardiographic indicators was higher in the group of patients with obesity.

Kibar et al., in a study in adolescents aged between 10 and 16 years, reported LA and LV dimensions significantly larger in the group with obesity in comparison with adolescents with normal weight ${ }^{16}$; however, these measurements remained within the normal limits for age. Although most measurements assessed in the present study remained within normal limits for age, significant changes were observed in the comparison between groups. The group with overweight showed a significantly higher mean for the LV diastolic diameter in comparison with the group with normal weight. In turn, in the children with obesity, not only a significantly higher mean was observed for LV diastolic diameter but also for interventricular septum diameter, LVm and LA, even after adjusting for age, gender, and height in the covariance analysis (Table 5), given that these are factors that might have an impact on cardiac dimensions. These results demonstrate the impact that the degree of body fat accumulation has on the changes experienced by the LV, with a larger number of alterations in children with obesity that in those with overweight. We consider that early interventions are required in patients with overweight, to avoid their progression to obesity and the increased cardiovascular risk this entails.

The characteristic LVm increase observed in obese patients is associated with the mechanical stress imposed by afterload sustained increase, which in the long term can lead to subendocardial fiber damage and cause regional functional alterations ${ }^{33}$. With $3 \mathrm{D}$ echocardiography, we observed not only a larger LVm but also a higher LV diastolic volume in the group with obesity, in comparison with the group with normal weight.

We did not observe alterations or significant differences with regard to LV systolic function conventional indicators between the groups, which was consistent with observations reported by other authors ${ }^{13,16}$. We know that conventional echocardiographic methods lack sufficient sensitivity to detect ventricular function early changes associated with obesity ${ }^{10}$. This is attributed to Simpson modified method-assessed LVEF inability to accurately detect early changes in the ventricular function in patients with obesity. Kibar and Di Salvo failed to find significant differences in LV diastolic function as assessed with mitral flow Doppler or TDI between patients with obesity and normal weight $t^{3}, 16$. Similarly, we did not observe significant differences in the LV diastolic function in the group of children with obesity when compared with the normal weight group.

Echocardiographic indicators' Z-scores were calculated considering a reference population from the US, which might have affected the sensitivity of these standards to detect alterations associated with obesity in this sample of Mexican children. However, echocardiographic indicator raw values (before being standardized to Z-scores) showed significant differences between groups, which were maintained after being adjusted for age, gender, and height. This highlights the importance of construecting reference standards for the $Z$ distribution of specific echocardiographic indicators for each population.

The assessment of myocardial deformation in obese patients using 2D speckle tracking echocardiography is relatively new ${ }^{34}$. Barbosa et al., using this echocardiographic method, found a significantly lower myocardial longitudinal strain in patients with obesity in comparison with subjects of normal weight matched by age and gender, in spite of no differences existing in $\mathrm{LVEF}^{15}$. In turn, Kibar et al. also reported a reduction in myocardial regional deformation in the septal and lateral wall, using $2 \mathrm{D}$ speckle tracking, in patients with obesity and normal LVEF ${ }^{16}$. The present study demonstrated significant differences in myocardial longitudinal strain means between the groups with obesity $(-20.9 \mathrm{vs}$. $-23.5 ; p<0.05)$ and overweight $(-21.9$ vs. -23.5 ; $p<0.05)$, when compared with the group with normal weight, without a LVEF decrease being observed. The number of LV compromised segments was larger inthe group of children with obesity than in those with Oyerweight, with apical, and middle segments being mainly affected. These results maintained their statistical sigignificance even after being adjusted for age, gender,and height in the analysis of covariance (Table 5). Recently, Balderrábano reported 34 severely obese adolescents, out of which $52 \%$ already had a LVEF $<55 \%$, and $78.9 \%$ had abnormal myocardial longitudinal strainivalues evaluated by $2 \mathrm{D}$ speckle tracking echocardiography ${ }^{35}$. With this previous observations, we considerthat 2D speckle tracking echocardiography is an important tool in the monitoring of the subclinical functional atterations the myocardium suffers in relation to overweight and obesity severity and evolution time ${ }^{36}$.

It is of the utmost importance for the reference ranges for the values derived from the measurement of 
myocardial deformity by $2 \mathrm{D}$ speckle tracking echocardiography at pediatric age to be established. These reference ranges allow the application of the technique to clinical practice. However, most studies in pediatrics still have an inconsistent methodology and small sample sizes ${ }^{37}$. In this regard, the fact that meta-analyses that report reference ranges in the pediatric population have chosen studies where even less $50 \%$ of patients had global longitudinal strain determined as an average of the measurement in all three (4-, 3-, and 2-chamber) apical projections stands out ${ }^{23}$. In addition, it cannot be definitively concluded that demographic variables do not influence on myocardial deformity data obtained at pediatric age ${ }^{23}$. The wide reference range reported for myocardial deformity values led us to consider a group of healthy patients as the control group in our study, and significant differences were found in myocardial longitudinal strain means between the groups with obesity $(-20.9$ vs. $-23.5 ; p<0.05)$ and overweight ( -21.9 vs. $-23.5 ; p<0.05)$, when compared to the normal weight group. Among the findings of the current study, we highlight the presence of early changes in myocardial deformity in obese and overweight children before they become apparent with conventional assessment methods. Studies with larger sample sizes and standardized methodology will be required in the future.

The dissemination and application of prevention measures aimed at modifying the diet and at the adoption of healthy lifestyle habits have great importance in the pediatric population, taking into account the increase in childhood obesity in recent decades. According to the results obtained in the present investigation, intervention measures and treatment should be early and timely started in overweight children, since as it was demonstrated in this work, they already present incipient changes, to avoid the appearance of more severe myocardial function alterations than those the child with obesity already has ${ }^{38}$.

Overweight and obesity treatment in pediatrics is mainly based on non-pharmacological measures and should include not only the adoption of a balanced and healthy diet that meets the nutritional needs of the child, with adequate control of servings and decreased consumption of sugary drinks and foods of high caloric content and low nutritional value but also the practice of regular physical activity and reduction of sedentary activities ${ }^{39}$. Pharmacological therapy in obese children is rather limited and is frequently associated with adverse effects ${ }^{40}$.

Our group continues the follow-up of these patients, which have been incorporated into a program of primary prevention strategies. Currently, we are carrying out a study that has as its main goal to assess the effect of a nutrition and physical activity education program on indicators of cardiac function and structure and cardiovascular risk markers in school children with overweight and obesity. The results of this still ongoing study are expected show the relevance of lifestyle changes as a priority measure for the control of overweight and obesity and cardiovascular risk management in the pediatric population.

2D speckle tracking echocardiography could be a useful tool to assess the impact of lifestyle modifications on global and regional myocardial LV function in patients with overweight and obesity.

\section{Limitations of the study}

The sample size was not representative of the Mexican pediatric population, which limits the generalization of the obtained data.

\section{Conclusions}

The present study demonstrated the presence of alterations in the left cavities' dimension and in myocardial longitudinal strain in children with obesity who were not hypertensive, even in the presence of normal LVEF. These results support the increasing usefulness of myocardial deformation assessment with $2 \mathrm{D}$ speckle tracking echocardiography in the early diagnosis of LV function alterations in this population.

With a smaller number of alterations in LV dimensions and function, overweight patients should be the main target in the implementation of excess weight secondary prevention measures and treatment to prevent its progression to obesity and the consequient deterioration of ventricular function.

Studies are required for the assessment of the possible regression of functional alterations acquired by the LV in patients with obesity and overweight once treatment is started and secondary prevention measures have been adopted.

\section{Conflicts of interest}

None.

\section{Funding}

The present investigation has not received specific aid from public or commercial sector agencies or non-profit entities. 


\section{Ethical disclosures}

Protection of people and animal subjects. The authors declare that no experiments were performed on humans or animals for this study.

Confidentiality of data. The authors declare that they have followed the protocols of their work center on the publication of patient data.

Right to privacy and informed consent. The authors have obtained written informed consent of the patients and/or subjects mentioned in the article.

\section{References}

1. Sánchez-Cruz JJ, Jimenez-Moleon JJ, Fernandez-Quezada F, Sánchez MJ. Prevalencia de obesidad infantil y juvenil en España en 2012. Rev Esp Cardiol. 2013;66(5):371-6.

2. Hernández-Ávila M, Rivera-Dommarco J, Shamah-Levy T, Cuevas-Nasu L, Gómez-Acosta L, Gaona-Pineda E, et al. Encuesta Nacional de Salud y Nutrición de medio camino 2016. Informe nacional de resultados. Cuernavaca, México: Instituto Nacional de Salud Pública. 2016.

3. Daniels SR. Complications of obesity in children and adolescents. Int $J$ Obes (Lond). 2009;33(Suppl 1):S60-5.

4. Bjorge T, Engeland A, Tverdal A, Smith GD. Body mass index in adolescence in relation to cause-specific mortality: a follow-up of 230,000 Norwegian adolescents. Am J Epidemiol. 2008;168:30-7.

5. Freedman DS, Patel DA, Srinivasan SR, Chen W, Tang R, Bond MG, et al. The contribution of childhood obesity to adult carotid intima-media thickness: the Bogalusa Heart Study. Int J Obes (Lond). 2008; 32(5): 749-56.

6. Owen CG, Whincup PH, Orfei L, et al. Is body mass index before middle age related to coronary heart disease risk in later life? Evidence from observational studies. Int J Obes (Lond). 2009;33(8):866-77.

7. Berenson GS, Srinivasan SR, Bao W, Newman WP, Tracy RE Wattigney WA, et al. Association between multiple cardiovascular risk factors and atherosclerosis in children and young adults. The Bogalusa Heart Study. N Engl J Med. 1998;338:1650-6.

8. Mahoney LT, Burns TL, Stanford W, Thompson BH, Witt JD, Rost CA, et al. Usefulness of the Framingham risk score and body mass index to predict early coronary artery calcium in young adults (Muscatine Study). Am J Cardiol. 2001;88:509-15.

9. Pascual M, Pascual DA, Soria F, Vicente T, Hernández AM, Tébar FJ, et al. Effects of isolated obesity in systolic and diastolic left ventricular function. Heart. 2003;89(10):1152-6.

10. Wong CY, O'Moore-Sullivan T, Leano R, Byrne N, Beller E, Marwick TH. Alterations of left ventricular myocardial characteristics associated with obesity. Circulation. 2004;110(19):3081-7.

11. Sutherland GR, Di Salvo G, Claus P, Bijnens B. Strain and Strain rate imaging: a new clinical approach to quantifying regional myocardial function. Am Soc Echocardiogr. 2004;17(7):788-802.

12. Mangner N, Scheuermann K, Winzer E, Wagner I, Hoellriegel R, Sandri $M$, et al. Childhood obesity: impact on cardiac geometry and function. JACC Cardiovasc Imaging. 2014;7(12):1198-205.

13. Di Salvo G, Pacileo G, Del Giudice EM, Natale F, Limongelli G, Verrengia $\mathrm{M}$, et al. Abnormal myocardial deformation properties in obese, non-hypertensive children: an ambulatory blood pressure monitoring, standard echocardiographic, and strain rate imaging study. Eur Heart $\mathrm{J}$. 2006;27(22):2689-95.

14. Vitarelli A, Martino F, Capotosto L, Martino E, Colantoni C, Ashurov R, et al. Early myocardial deformation changes in hypercholesterolemic and obese children and adolescents: a 2D and 3D speckle tracking echocardiography study. Medicine (Baltimore). 2014;93(12):e71.

15. Barbosa JA, Mota CC, Simões AC, Nunes C, Barbosa MM. Assessing pre-clinical ventricular dysfunction in obese children and adolescents: the value of speckle tracking imaging. Eur Heart $\mathrm{J}$ Cardiovasc Imaging. 2013;14(9):882-9.

16. Kibar AE, Pac FA, Ece I, Oflaz MB, Ballı Ş, Bas VN, et al. Effect of obesity on left ventricular longitudinal myocardial strain by speckle tracking echocardiography in children and adolescents. Balkan Med $\mathrm{J}$. 2015;32(1):56-63.

17. Ortiz-Marrón H, Cuadrado-Gamarra JI, Esteban-Vasallo M, Cortés-Rico O, Sánchez-Díaz J, Galán-Labaca I. Estudio Longitudinal de Obesidad Infantil (ELOIN): diseño, participación y características de la muestra. Rev Esp Cardiol. 2016;69(5):521-3.
18. The International Society for the Advancement in Kinanthropometry (ISAK). International Standards for Anthropometric Assessment. Underdale, SA, Australia: ISAK; 2001;1-133.

19. de Onis M, Onyango AW, Borghi E, Siyam A, Nishida C, Siekmānn J. Development of a WHO growth reference for school-aged children and adolescents. Bull World Health Organ. 2007;85(9):660-7.

20. National High Blood Pressure Education Program Working Group on High Blood Pressure in Children and Adolescents. The fourth report on the diagnosis, evaluation, and treatment of high blood pressure in children and adolescents. Pediatrics. 2004:114:555-76.

21. Pettersen MD, Du W, Skeens ME, Humes RA. Regression equations for calculation of $z$ scores of cardiac structures in a large cohort of healthy infant's children, and adolescents: an echocardiographic study. J Am Soc Echocardiogr. 2008;21:922-34.

22. Lopez L, Colan SD, Frommelt PC, Ensing GJ, Kendall K, Younoszail AK, et al. Recommendations for quantification methods during the performance of a pediatric echocardiogram: a report from the Pediatric Measurements Writing Group of the American Society of Echocardiography Pediatric and Congenital Heart Disease Council. J Am Soc Echocardiogr. 2010;23(5):465-95.

23. Levy PT, Machefsky A, Sanchez AA, Patel MD, Rogal S, Fowler S, et al. Reference Ranges of Left Ventricular Strain Measures by Two-Dimensional Speckle Tracking Echocardiography in Children: A Systematic Review and Meta-Analysis. J Am Soc Echocardiogr. 2017;29(3):209-25.

24. Collier P, Phelan D, Klein A. A Test in Context: Myocardial Strain Measured by Speckle-Tracking Echocardiography. J Am Coll Cardiol.2017; 69(8):1043-56.

25. Cerqueira MD, Weissman NJ, Dilsizian V, Jacobs AK, Kaul S, Laskeyy WK, et al. Standardized myocardial segmentation and nomenclature for tomographic imaging of the heart. Circulation. 2002;105(4):539-42.

26. Aceves-Martins M, Llauradó E, Tarro L, Solá R, Giralt M. Obesity-promoting factors in Mexican children and adolescents: Challenges and opportunities. Glob Health Action. 2016;9:29625.

27. Alpert MA. Obesity cardiomyopathy: pathophysiology and evolution of the clinical syndrome. Am J Med Sci. 2001;321(4):225-36.

28. Rajapurohitam V, Javadov S, Purdham DM, Kirshenbaum $L A$, Karmazyn M. An autocrine role for leptin in mediating the cardiomyocyte hypertrophic effects of angiotensin II and endothelin-1. J Mol Cell Cardiol. 2006;41(2):265-74

29. López-Jiménez F, Cortés-Bergoderi M. Update: systemic diseasês and the cardiovascular system (i): obesity and the heart. Rev Esp Cardiol. $2011 ; 64(2): 140-9$

30. Huang Y, Walker KE, Hanley F, Narula J, Houser SR, Tulenko TN Cardiac systolic and diastolic dysfunction after a cholesterol-rich diet. Circulation. 2004;109(1):97-102.

31. Sáez-Meabe Y, Lafita-Bernar M, Vacas-Rius M, Sagastagoitia-Gorostiza JD, Pablo-Sáez de Lafuente Chivite J, Santos-Gutiérrez M, et al. Valores de colesterol HDL en la población infantil y riesgo trombótico. An Pediatr. 2007;67(6):567-71.

32. Pacifico L, Bonci E, Andreoli G, Romaggioli S, Di Miscio R, Lombardo CV, et al. Association of serum triglyceride-to-HDL cholesterol ratio with carotid artery intima-media thickness, insulin resistance and nonalcoholic fatty liver disease in children and adolescents. Nutr Metab Cardiovasc Dis. 2014;24(7):737-43.

33. Kosmala W, Wong C, Kuliczkowska J, Leano R, Przewlocka-Kosmala M, Marwick TH. Use of body weight and insulin resistance to select obese patients for echocardiographic assessment of subclinical left ventricular dysfunction. Am J Cardiol. 2008; 101(9):1334-40.

34. Geyer H, Caracciolo G, Abe H, Wilansky S, Carerj S, Gentile F, et al. Assessment of myocardial mechanics using speckle tracking echocardiography: fundamentals and clinical applications. J Am Soc Echocardiogr. 2010;23(4):351-69.

35. Balderrábano N, Del Rio B, Navarrete E, Berber A, Méndez N. Evaluation of the left ventricle longitudinal deformity using myocardial-tracking signals in severely obese adolescents. Cardiol Young. 2016; 26(4):749-53.

36. Nakajima T, Jujioka S, Tokunaga K, Hirobe K, Mutsuzawa Y, Tarui S. Non-invasive study of left ventricular performance in obese patients: influence of duration of obesity. Circulation. 1985;71(3):481-6.

37. Cantinotti M, Kutty S, Giordano R, Assanta N, Murzi B, Crocetti M, et al. Review and status report of pediatric left ventricular systolic strain and strain rate nomograms. Heart Fail Rev. 2015;20(5):601-12.

38. Vázquez-Antona CA. La prevención primaria de la enfermedad cardiovascular inicia en la infancia. Arch Cardiol Mex. 2007;77(52):7-10

39. Steinberger J, Daniels S, Hagberg N, Isasi CR, Kelly AS, Lloyd-Jones D, et al. Cardiovascular Health Promotion in Children: Challenges and Opportunities for 2020 and Beyond: A Scientific Statement for Healthcare Professionals from the American Heart Association. Circulation. 2016;134(12):e236-55

40. Greydanus DE, Agana M, Kamboj MK, Shebrain S, Soares N, Eke Ret al Pediatric obesity: Current concepts. Disease-a-Month. 2018;64(4):98-156. 